\title{
Avaliação de Modelos Matemáticos para o Estudo da Cinética de Passagem de Partículas e de Fluidos por Bovinos em Pastagem Recebendo Suplementos Contendo Diferentes Níveis de Proteína Não-Degradável no Rúmen
}

\author{
José Carlos Pereira1, Marinaldo Divino Ribeiro², Ricardo Augusto Mendonça Vieira ${ }^{3}$, \\ Bevaldo Martins Pacheco 4
}

\begin{abstract}
RESUMO - Estudaram-se os comportamentos dos parâmetros da cinética de passagem de partículas e de fluidos em bovinos mantidos em pastagem de Brachiaria brizantha, em duas épocas (época 1 = meses de maio, junho e julho/2000; e época 2 = meses de março, abril e maio/2001), recebendo suplementos contendo diferentes níveis de proteína não-degradável no rúmen (PNDR). Na época 1 os animais foram alimentados com suplementos contendo 20, 40 e 60\% de PNDR, feno de Brachiaria brizantha e mistura mineral ad libitum, enquanto na época 2, foram distribuídos nos tratamentos: $\mathrm{T}_{0}=$ pastagem de capim-braquiária + mistura mineral ad libitum; $\mathrm{T}_{40}=$ pastagem + suplemento com $40 \%$ de PNDR; e $\mathrm{T}_{60}=$ pastagem + suplemento com $60 \%$ de PNDR. Na estimativa da taxa de passagem de partículas pelo rúmen, utilizouse como indicador o Cr-mordente, enquanto a cinética de passagem de fluidos foi estimada com Co-EDTA, durante três períodos, de agosto a setembro/2001, utilizando-se os mesmos animais e tratamentos da época 2. As estimativas dos parâmetros da cinética de passagem de partículas foram determinadas a partir do ajuste dos dados aos modelos bicompartimentais (G1G1, G2G1, G3G1, G4G1, G5G1 e G6G1), enquanto, para a cinética de passagem de fluidos, foi utilizado o modelo G1G1. Os critérios de escolha do melhor modelo foram a freqüência observada dos valores mínimos para o quadrado médio residual, obtido com os ajustes dos diferentes modelos e o número de corridas de sinal dos resíduos padronizados. Os modelos G2G1 e G3G1 mostraram-se mais eficientes na determinação das estimativas dos parâmetros de cinética de passagem de partículas, nas épocas 1 e 2, respectivamente. As estimativas do tempo médio de retenção ruminal de partículas e de fluidos não foram influenciadas pelos diferentes níveis de PNDR do suplemento.
\end{abstract}

Palavras-chave: modelos, proteína de escape, suplemento protéico, taxa de passagem

\section{Evaluation of Mathematical Models for Estimating the Kinetics of Ruminal Passage of Particles and Liquid of Grazing Steers Supplemented with Different Rumen- Undegradable Protein Levels}

\begin{abstract}
The effects of supplements containing different rumen-undegradable protein(RUP) levels on the ruminal passage rate of particles and liquid of steers grazing Brachiaria brizantha were evaluated in this study. Samples were collected in two seasons of the year (season 1 - May, June and July/2000 and season 2 - March, April and May/2001). In season 1, animals were housed in individual stalls and were fed supplements containing 20, 40 or 60\% RUP plus Brachiaria brizantha hay and had free access to a mineral mix. In season 2, steers were distributed to one of three treatments as follows: $\mathrm{T}_{0}=$ Brachiaria brizantha pasture + ad libitum mineral mix, $\mathrm{T}_{40}=$ pasture $+40 \% \mathrm{RUP}$ supplement, or $\mathrm{T}_{60}=$ pasture + 60\% RUP supplement. Chromium mordant was used to estimate ruminal passage rate of particles; fluid passage rate was estimated using CoEDTA during three periods from August to September/2001 using the same animals of season 2. Estimation of the kinetic parameters of ruminal passage of particles was obtained by adjusting data to different bicompartimental models (G1G1, G2G1, G3G1, G4G1, G5G1 e G6G1) while the model G1G1 was used to estimate the kinetic parameters of ruminal passage of liquid. The criteria to choose the best model were the observed frequency of minimum values for the mean residual square obtained with the adjustment of different models and the number of signal runs of standardized residues. The models G2G1 e G3G1 were the most efficient to estimate the kinetic parameters of ruminal passage of particles in seasons 1 and 2, respectively. Different supplement RUP levels did not affect the estimation of mean ruminal retention time of both particles and liquid.
\end{abstract}

Key Words: escape protein, models, protein supplement, passage rate

\section{Introdução}

No interior do rúmen, encontra-se em atividade um sistema complexo, com conteúdos heterogêneos de digesta líquida e sólida e estratificação deste conteúdo em diferentes camadas, nas direções dorsoventral e crânio-ventral, tornando o processo digestivo nos ruminantes um sistema dinâmico que envolve a entrada de alimentos no rúmen e a saída de líquidos, microrganismos e resíduos não-digeridos.

\footnotetext{
${ }^{1}$ Professor Titular do Departamento de Zootecnia da UFV. Pesquisador do CNPq. E.mail: jcarlos@ufv.br

2 Estudante de Doutorado em Zootecnia da UFV. Endereço para correspondências: maldor@vicosa.ufv.br

3 Professor Associado do Laboratório e Zootecnia e Nutrição Animal da UENF. Pesquisador do CNPq.

${ }^{4}$ Pesquisador do Instituto Capixaba de Pesquisa Agropecuária - INCAPER.
} 
Neste sentido, os movimentos de contração e relaxamento das paredes musculares e pilares contribuem para manter a natureza contínua do processo de fermentação (Van Soest, 1994). Isso resulta principalmente da contribuição destes movimentos em: 1) dispersar o bolo alimentar ingerido; 2) misturar a saliva com a digesta, promovendo equilíbrio eficiente do pH ruminal; 3) ajudar a inocular o alimento ingerido com os microrganismos; 4) assistir na fragmentação das partículas do alimento; e 5) facilitar a remoção dos produtos da digestão (Reid,1963, citado por Thiago \& Gill, 1990). O outro ponto importante é que o movimento da partícula no ambiente ruminal é uma conseqüência de sua forma, seu tamanho, sua densidade e sua viscosidade, de modo que partículas pesadas tendem a depositar-se no saco ventral do rúmen, enquanto partículas leves flutuam e constituem a malha filtrante do rúmen, também chamada de raft (Thiago \& Gill,1990).

Segundo Martz \& Belyea (1996), os ruminantes despedem um esforço considerável para mover a digesta. A densidade, a porcentagem de parede celular, a pressão osmótica e o $\mathrm{pH}$ podem afetar a propulsão, ressaltando-se que partículas densas podem ir para o fundo e resistir ao escape, enquanto a parede celular pode reduzir a digestão e a passagem. A pressão osmótica ou o $\mathrm{pH}$ podem afetar a eficiência dos processos digestivos e o ritmo dos músculos do trato gastrintestinal. Segundo esses autores, as contrações ruminais podem ser mais freqüentes com digesta de forragem nova que com forragem madura de baixa qualidade, uma vez que as contrações do rúmen não dependem de ruminação. O fato de a motilidade ser incrementada com forragem de alta qualidade e o fluxo por contração ser aumentado em virtude de mudanças na consistência física explicaria parcialmente a passagem rápida observada com gramíneas de alta qualidade.

Nas últimas décadas, diversos modelos matemáticos têm sido desenvolvidos com o objetivo de melhor representar e predizer o evento biológico, a taxa de passagem de partículas e fluidos. Esses modelos permitem a obtenção das estimativas dos parâmetros da cinética de passagem, a partir do ajuste dos dados a diferentes modelos, denominados bicompartimentais, como aqueles descritos por Pond et al. (1988) e Moore et al. (1992), que explicam o mecanismo de escape das partículas e dos fluidos da câmara fermentativa ruminal, e contribuem para melhorar a predição e o ajuste do aporte de nutrientes às exigências do animal. Isso é importante, especialmente no caso de forrageiras tropicais, que, geralmente, apresentam baixa degradação da fibra e lenta taxa de passagem ao longo do trato gastrintestinal, resultando, conseqüentemente, em baixo consumo voluntário e desempenho animal.

Embora na literatura têm-se encontrado efeitos benéficos da suplementação sobre a taxa de passagem (McCollum \& Galyean, 1985), efeitos nulos sobre esta variável são freqüentemente relatados (Judkins et al., 1987; Hess et al., 1996). Como visto, as informações disponíveis na literatura são limitadas e pouco conclusivas no que diz respeito à influência da suplementação protéica sobre os parâmetros da cinética de passagem de partículas e fluidos das diferentes espécies forrageiras, o que justifica esforços investigativos para se determinar a relação entre os níveis de proteína não-degradável no rúmen e estas variáveis.

Diante do exposto, este trabalho foi conduzido para se avaliar modelos matemáticos para predição da cinética de passagem de partículas e de fluidos em bovinos mantidos em pastagem de Brachiaria brizantha suplementada com diferentes níveis de proteína não-degradável no rúmen.

\section{Material e Métodos}

Foram conduzidos dois experimentos na região do cerrado goiano, no Instituo Melon de Estudos e Pesquisas, em Silvânia - Goiás, para se avaliar a taxa de passagem de partículas: um durante os meses de maio, junho e julho/2000, correspondentes à época 1; e outro durante os meses de março, abril e maio/2001, relativos à época 2 . Na época 1 , os animais foram alojados em baias individuais e receberam suplementos contendo 20, 40 e $60 \%$ de PNDR, feno de Brachiaria brizantha e mistura mineral à vontade, enquanto, na época 2, foram distribuídos nos tratamentos: $\mathrm{T}_{0}=$ pastagem de Brachiaria brizantha + mistura mineral à vontade; $\mathrm{T}_{2}=$ pastagem + suplemento com $40 \%$ de PNDR e; $\mathrm{T}_{3}=$ pastagem + suplemento com $60 \%$ de PNDR. Os ingredientes, a quantidade oferecida e a composição das dietas estão descritos na Tabela 1 e 2, para ambas as épocas, respectivamente. 
As amostras utilizadas para complexação da fibra com cromo, na época 1 , foram provenientes do pastejo simulado, em área de pastagem de Brachiaria brizantha, enquanto as amostras referentes à época 2 foram obtidas por meio de novilhos fistulados no esôfago na mesma área experimental.

Após as coletas em cada período, as amostras da forrageira do pastejo simulado foram submetidas à moagem, à secagem à temperatura de $60 \pm 5^{\circ} \mathrm{C}$, por 72 horas, e foram armazenadas para complexação da fibra. No caso da extrusa, as amostras foram coletadas e processadas conforme a técnica descrita por Pereira et al. (2002).

As amostras utilizadas para estimativa da cinética de passagem de partículas foram tratadas com dicromato de potássio, conforme metodologia descrita por Udén et al. (1980), sendo, então, administradas a três animais por tratamento e por período, em dose única, via fístula ruminal, e acondicionadas em saco de papel, na quantidade de $150 \mathrm{~g}$.

Tabela 1 - Composição dos suplementos e quantidade fornecida nas épocas 1 e 2

Table 1 - Composition and amount of supplement in seasons 1 and 2

\begin{tabular}{|c|c|c|c|c|c|}
\hline \multirow[t]{3}{*}{$\begin{array}{l}\text { Ingrediente } \\
\text { Ingredient }\end{array}$} & \multicolumn{5}{|c|}{$\begin{array}{c}\text { Suplemento } \\
\text { Supplement }\end{array}$} \\
\hline & \multicolumn{3}{|c|}{$\begin{array}{l}\text { Época } 1^{(1)} \\
\text { Season } 1^{(1)}\end{array}$} & \multicolumn{2}{|c|}{$\begin{array}{l}\text { Época } 2^{(1)} \\
\text { Season } 2^{(1)}\end{array}$} \\
\hline & $\mathrm{T}_{20}$ & $\mathrm{~T}_{40}$ & $\mathrm{~T}_{60}$ & $\mathrm{~T}_{40}$ & $\mathrm{~T}_{60}$ \\
\hline $\begin{array}{l}\text { Fubá de milho } \\
\text { Ground corn }\end{array}$ & 872 & 727 & 780 & 476 & 890 \\
\hline $\begin{array}{l}\text { Glúten de milho } \\
\text { Corn gluten meal }\end{array}$ & 0 & 51 & 220 & 0 & 108 \\
\hline $\begin{array}{l}\text { Gérmen de milho } \\
\text { Corn germ }\end{array}$ & 0 & 0 & 0 & 376 & 0 \\
\hline $\begin{array}{l}\text { Farelo de soja } \\
\text { Soybean meal }\end{array}$ & 98 & 222 & 0 & 62 & 0 \\
\hline $\begin{array}{l}\text { Farelo de trigo } \\
\text { Wheat bran }\end{array}$ & 0 & 0 & 0 & 84 & 0 \\
\hline $\begin{array}{l}\text { Uréia } \\
\text { Urea }\end{array}$ & 30 & 0 & 0 & 2 & 0 \\
\hline $\begin{array}{l}\text { Oferta }^{2} \\
\text { Fed }^{2}\end{array}$ & 2989 & 2985 & 3.005 & 1780 & 1800 \\
\hline
\end{tabular}

${ }^{1} \mathrm{~g} \mathrm{~kg}^{-1} \mathrm{MS}(D M) ;{ }^{2} \mathrm{~g} \mathrm{MS} \mathrm{dia}^{-1}$ (g DM day $\left.{ }^{-1}\right)$.
O preparo do indicador cobalto-EDTA, utilizado na estimação da taxa de passagem de fluidos, seguiu a metodologia descrita por Udén et al. (1980). Posteriormente, o indicador foi fornecido a três animais por tratamento, em três períodos, compreendidos entre agosto e setembro de 2001, em dose única, pela manhã, na quantidade de 25 g de Co-EDTA, diluídos em 400 mL de água destilada, via fístula ruminal. Os animais foram mantidos na mesma pastagem, recebendo os mesmos tratamentos experimentais referentes à época 2 descritos para taxa de passagem de partículas.

As fezes foram coletadas nos tempos zero (imediatamente após a administração da fibra complexada com cromo), 8, 16, 24, 28, 32, 36, 40, 44, 48, 52, 56, 60, 64, 72, 80, 88, 100, 112, 124 e 148 h, para estimação dos parâmetros de cinética de passagem de partículas. No caso da cinética de passagem de fluidos, as fezes foram coletadas nesses mesmos tempos, acrescentando-se os tempos 4, 12 e 20 horas. Após a coleta nos respectivos tempos, as amostras foram secas em estufa de ventilação forçada à temperatura de $60 \pm$ $5^{\circ} \mathrm{C}$, durante 72 a 96 horas, processadas em moinho com peneira de crivo de $1 \mathrm{~mm}$ e armazenadas para as análises subseqüentes. As amostras de fezes foram submetidas à análise de seus teores de cromo, pelo método de Williams et al. (1962), enquanto os conteúdos de cobalto foram dosados e lidos conforme o manual Varian (1989), sendo expressos em mg kg-1 de MS fecal.

As estimativas dos parâmetros da cinética de passagem de partículas foram determinadas a partir do ajuste dos dados a diferentes modelos bicompartimentais, que descrevem o mecanismo de escape de partículas com probabilidade gama distribuída no primeiro compartimento (pressupondo-se que corresponda à malha filtrante do rúmen ou raft, constituída de partículas recém-ingeridas) e exponencialmente distribuída no segundo compartimento (pressupondo-se que corresponda à parte ventral do rúmen, constituída de partículas pequenas dispersas na fase líquida). Considerando-se as ordens de dependência de tempo para a função gama, $\Gamma(n, \lambda, t)$, os modelos GnG1 podem ser obtidos pela equação abaixo, fazendo n variar de 1 a 6 (Pond et al., 1988; Moore et al., 1992):

$$
G n G 1: C(t)=C\left[\delta^{n} \exp (-k T)-\exp (-\lambda T) \sum_{i=1}^{n} \delta^{i}(\lambda T)^{n-i} /(n-i) !\right]+e_{j}
$$

\footnotetext{
R. Bras. Zootec., v.34, n.6, p.2475-2485, 2005 (supl.)
} 
Tabela 2 - Valores médios de proteína bruta (PB), proteína insolúvel em detergente neutro (PIDN), extrato etéreo (EE), matéria mineral (MM), fibra em detergente neutro (FDN), carboidratos totais (CT), carboidratos fibrosos (CF) e carboidratos não-fibrosos (CNF) dos suplementos e do feno de capim-braquiária, nas épocas 1 e $2^{1 /}$

Table 2 - Average values of crude protein (CP), neutral detergent insoluble protein (NDIP), etherl extract (EE), mineral matter (MM), neutral detergent fiber (NDF), total carbohydrates (TC), fiber carbohydrates (FC), and nonfiber carbohydrate (NFC) of supplements and Brachiaria brizantha hay in seasons 1 and $2^{(1)}$

\begin{tabular}{|c|c|c|c|c|c|c|}
\hline \multirow[t]{3}{*}{$\begin{array}{l}\text { Nutriente } \\
\text { Nutrient }\end{array}$} & \multicolumn{5}{|c|}{$\begin{array}{l}\text { Suplemento } \\
\text { Supplement }\end{array}$} & \multirow[t]{3}{*}{$\begin{array}{c}\text { Feno } \\
\text { Hay }\end{array}$} \\
\hline & \multicolumn{3}{|c|}{$\begin{array}{l}\text { Época } 1^{(1)} \\
\text { Season } 1^{(1)}\end{array}$} & \multicolumn{2}{|c|}{$\begin{array}{l}\text { Época } 2^{(1)} \\
\text { Season } 2^{(1)}\end{array}$} & \\
\hline & $\mathrm{T}_{20}$ & $\mathrm{~T}_{40}$ & $\mathrm{~T}_{60}$ & $\mathrm{~T}_{40}$ & $\mathrm{~T}_{60}$ & \\
\hline $\mathrm{PB}(C P)$ & 237 & 231 & 237 & 150 & 169 & 29 \\
\hline PIDN (IPND) & 9 & 10 & 13 & 16 & 10 & 4 \\
\hline $\operatorname{PIDN}^{3}(I P N D)$ & 4 & 4 & 5 & 11 & 6 & 14 \\
\hline $\mathrm{EE}$ & 32 & 29 & 30 & 38 & 35 & 4 \\
\hline MM & 18 & 27 & 13 & 28 & 13 & 58 \\
\hline $\mathrm{FDN}(N D F)$ & 114 & 122 & 111 & 178 & 109 & 824 \\
\hline CT (TC) & 793 & 734 & 741 & 786 & 782 & 909 \\
\hline $\mathrm{CF}(F C)$ & 102 & 108 & 96 & 157 & 97 & 809 \\
\hline $\mathrm{CF}^{4}(F C)$ & 13 & 15 & 13 & 20 & 12 & 89 \\
\hline CNF (NFC) & 691 & 626 & 645 & 629 & 685 & 100 \\
\hline
\end{tabular}

${ }^{1}$ Análises realizadas no Instituto Melon de Estudos e Pesquisas.

2 Teores expressos em $\mathrm{g} \mathrm{kg}^{-1} \mathrm{MS}$.

$3 \%$ da PB (\% CP).

$4 \%$ dos CT (\% TC).

${ }^{1}$ Samples were analyzed at Melon Research Center.

2 Contents expressed in $\mathrm{g} \mathrm{kg}^{-1} \mathrm{DM}$.

em que $C(t)$ é a concentração do indicador na matéria seca fecal, $C$ (mg kg-1 MS fecal), a concentração inicial do indicador no segundo compartimento do rúmen; $\lambda\left(\mathrm{h}^{-1}\right)$, a taxa de passagem no compartimento com probabilidade de escape de partículas gama distribuída; $\mathrm{k}\left(\mathrm{h}^{-1}\right)$, a taxa de passagem no compartimento com probabilidade de escape de partículas exponencialmente distribuída; $\mathrm{t}(\mathrm{h})$, o tempo após o fornecimento do indicador; $\delta=\lambda /(\lambda-\mathrm{k}) ; T=t-\tau$, uma variável auxiliar, em que $\tau$ é o tempo de trânsito do indicador entre a saída do segundo compartimento e sua primeira detecção na matéria fecal (h); e $e_{i}$, o erro aleatório associado à j-ésima observação. Neste modelo geral, convencionalmente supõe-se que $\mathrm{k}<\lambda$.

Os modelos GnG1, gerados ao variar n entre 1 e 6 , são simétricos em relação às taxas de passagem $\lambda$ e $\mathrm{k}$. Assim, nos casos em que os valores de $\lambda$ tendem a $\mathrm{k}$, estas expressões resultam em uma indeterminação do tipo $0 / 0$, sendo necessária a reparametrização por meio da aplicação da regra de L'Hôpital, chegando-se à regra geral descrita a seguir: em que $\theta$ corresponde à taxa de passagem utilizada nos casos em que $\lambda$ tendeu a $\mathrm{k}$.

Os parâmetros $\lambda, K, \tau$ e $C$ foram estimados por meio do algoritmo de Marquardt, utilizando-se o método iterativo de mínimos quadrados não-lineares do programa SAS (1997), conforme sugerido por Moore et al. (1992). As combinações das 27 observações correspondentes aos três tratamentos, três animais e três períodos foram submetidas ao ajuste dos seis modelos, tendo sido os critérios de escolha do melhor modelo a freqüência observada dos valores mínimos para o quadrado médio residual obtido com os ajustes dos mesmos (Pond et al., 1988; Moore et al., 1992; Huhtanen \& Kukkonen, 1995) e o número de corridas de sinal dos resíduos padronizados (Draper \& Smith, 1966). Desta forma, os modelos selecionados nas duas épocas foram empregados para obtenção das estimativas dos tempos médios de retenção ruminal de partículas (TMRR), de acordo com a expressão (Lira, 2000):

$$
G n G 1: C(t)=C \theta^{n} T^{n} \exp (-\theta T) /(n !)+e_{j}
$$

$$
\operatorname{TMRR}, \mathrm{h}=\frac{\mathrm{n}}{\lambda}+\frac{1}{\mathrm{k}}
$$


em que $n$ representa a ordem de dependência da função gama.

As estimativas dos parâmetros de cinética de passagem de fluidos foram obtidas por meio do ajuste do modelo descrito na equação 1 . Nos casos em que os valores de $\lambda$ tenderam a $k$, procedeu-se à reparametrização da equação 1 , com a aplicação da regra de L'Hôpital, chegando-se à equação 2. O tempo médio de retenção da fase líquida (TMRL) foi calculado de acordo com a expressão:

$$
\text { TMRL, } h=\frac{1}{k_{l}}
$$

em que $\mathrm{k}_{l}\left(\mathrm{~h}^{-1}\right)$ representa a taxa de passagem de fluidos pelo rúmen-retículo.

Assim como para as concentrações de cromo, foram traçados perfis de excreção do cobalto para que se pudesse fazer julgamento crítico da dispersão dos dados e eliminação daqueles cuja representação gráfica não correspondia ao evento real. Posteriormente, as concentrações de cromo e de cobalto nas fezes foram corrigidas para suas concentrações obtidas nos tempos zero (imediatamente após o fornecimento do indicador) e 148 horas, respectivamente.

As variáveis TMRR e TMRL foram avaliadas quanto à dispersão dos dados e verificadas para o ajustamento ao modelo sugerido por Brody (1945) e por Kleiber (1975).

Utilizou-se a estatística $t$ para construção dos intervalos de confiança para os parâmetros de cinética de passagem de partículas, adotando-se $1-\alpha=0,95$.

\section{Resultados e Discussão}

O comportamento das curvas nos diferentes modelos bicompartimentais está representado nas Tabelas 3 e 4, para a época 1, e nas Tabelas 3 e 5, para a época 2.

Considerando-se as freqüências observadas dos valores mínimos para o quadrado médio residual como o primeiro critério na escolha do modelo a ser utilizado na descrição da cinética de passagem de partículas (Van Milgen et al., 1991), pode-se inferir que os modelos G2G1 e G6G1 (época 1) e os modelos G3G1 e G6G1 (época 2) foram os mais apropriados, por apresentarem maior freqüência de valores mínimos para o quadrado médio residual.
A persistência da melhor qualidade de ajuste dos modelos G2G1 e G6G1 (época 1) e dos modelos G3G1 e G6G1 (época 2) torna-se evidente ao analisar a distribuição das curvas de acordo com o número de corridas de sinal dos resíduos padronizados, cujas estimativas de freqüências acumuladas foram semelhantes para 12 corridas de sinal (Tabelas 4 e 5). Estes critérios, no entanto, não contemplam o fato de o aumento na ordem de dependência da função gama influenciar o pico e as fases ascendentes e descendentes da curva (Pond et al., 1988; Ellis et al., 1994; Huhtanen \& Kukkonen, 1995), o que resulta na redução sistemática do tempo de trânsito (Figuras 1a e 2a), no aumento da taxa de passagem de partículas com probabilidade de escape gama distribuída (Figuras 1b e 2b) e, conseqüentemente, na superestimação do tempo médio de retenção ruminal. Portanto, a opção pelo modelo mais simples, com menor n, permite a obtenção de estimativas mais verossímeis dos parâmetros, pois os eventos da retenção do indicador no rúmen-retículo e de seu trânsito, em fluxo laminar pelo restante do trato gastrintestinal, são mais bem explicados pelo modelo.

Esta escolha do modelo mais simples também foi recomendada por Moore et al. (1992), embora pautada apenas no critério de maior freqüência de valores de quadrados mínimos. No caso das estimativas dos

Tabela 3 - Distribuição das curvas, de acordo com a freqüência dos mínimos valores observados para o quadrado médio residual obtido para os diferentes modelos (G1G1, G2G1, G3G1, G4G1, G5G1 e G6G1) ajustados aos perfis de excreção fecal do indicador de fase sólida, para as épocas 1 e 2

Table 3 - Distribution of curves according to the frequency of the minimum observed values for mean residual square obtained for different models (G1G1, G2G1, G3G1, G4G1, G5G1 e G6G1) adjusted to excretion profile of the solid phase marker on seasons 1 and 2

\begin{tabular}{lcc}
\hline $\begin{array}{l}\text { Modelo } \\
\text { Model }\end{array}$ & $\begin{array}{c}\text { Época 1 } \\
\text { Season 1 }\end{array}$ & $\begin{array}{c}\text { Época 2 } \\
\text { Season 2 }\end{array}$ \\
\hline \multicolumn{3}{c}{$\begin{array}{c}\text { Freqüência } \\
\text { Frequency }\end{array}$} \\
G1G1 & \multicolumn{2}{c}{ G } \\
G2G1 & 4 & 2 \\
G3G1 & 8 & 7 \\
G4G1 & 2 & 5 \\
G5G1 & 2 & 2 \\
G6G1 & 2 & 9 \\
\hline
\end{tabular}


Tabela 4 - Distribuição das curvas, de acordo com o número de corridas de sinal dos resíduos padronizados para cada modelo (G1G1, G2G1, G3G1, G4G1, G5G1 e G6G1) ajustado aos perfis de excreção fecal do indicador de fase sólida, para a época 1

Table 4 - Distribution of curves according to the number of signal run of the standardized residues for each model (G1G1, G2G1, G3G1, G4G1, G5G1 and G6G1) adjusted to the fecal excretion profiles of the solid phase marker for season 1

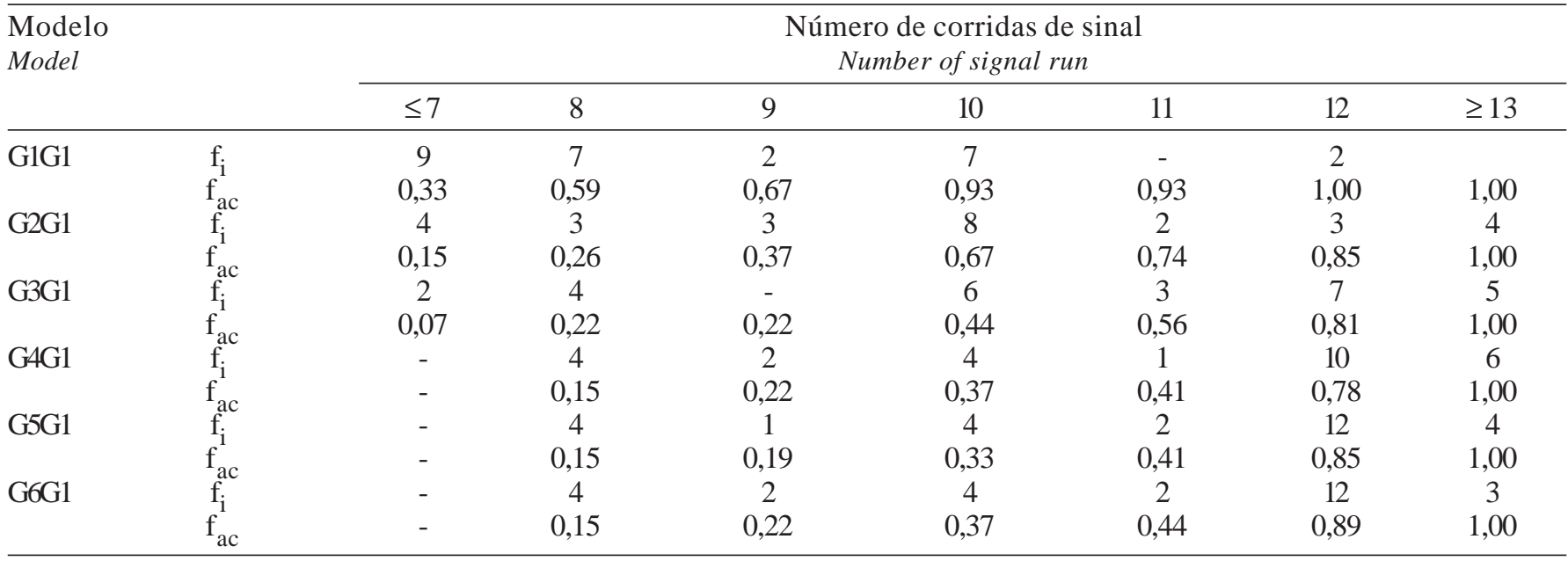

$f_{i}$ representa a freqüência observada e $f_{a c}$ corresponde à estimativa da freqüência acumulada.

$f_{i}$ represents the observed frequency and $f_{a c}$ the estimation of accumulated frequency.

Tabela 5 - Distribuição das curvas, de acordo com o número de corridas de sinal dos resíduos padronizados para cada modelo (G1G1, G2G1, G3G1, G4G1, G5G1 e G6G1) ajustado aos perfis de excreção fecal do indicador de fase sólida, para a época 2

Table 5 - Distribution of curves according to the number of signal run of the standardized residues for each model (G1G1, G2G1, G3G1, G4G1, G5G1 and G6G1) adjusted to the fecal excretion profiles of the solid phase marker for season 2

\begin{tabular}{|c|c|c|c|c|c|c|c|c|c|}
\hline \multirow[t]{2}{*}{$\begin{array}{l}\text { Modelo } \\
\text { Model }\end{array}$} & \multicolumn{6}{|c|}{$\begin{array}{l}\text { Número de corridas de sinal } \\
\text { Number of signal run }\end{array}$} & \multirow[b]{2}{*}{12} & \multirow[b]{2}{*}{13} & \multirow[b]{2}{*}{$\geq 14$} \\
\hline & $\leq 6$ & 7 & 8 & 9 & 10 & 11 & & & \\
\hline G1G1 & 0,52 & 0,63 & 0,78 & 0,85 & 0,96 & 1,00 & 1,00 & 1,00 & 1,00 \\
\hline \multirow[t]{2}{*}{ G2G1 } & 4 & 5 & 7 & 3 & 3 & 3 & 1 & 1 & - \\
\hline & 0,15 & 0,33 & 0,59 & 0,70 & 0,82 & 0,93 & 0,96 & 1,00 & 1,00 \\
\hline G3G1 & 0,04 & 0,18 & 0,41 & 0,56 & 0,78 & 0,93 & 0,96 & 1,00 & - \\
\hline \multirow[t]{2}{*}{ G4G1 } & 2 & 3 & 5 & 5 & 7 & 1 & 2 & - & 2 \\
\hline & 0,07 & 0,18 & 0,37 & 0,56 & 0,82 & 0,85 & 0,93 & 0,93 & 1,00 \\
\hline \multirow[t]{2}{*}{ G5G1 } & 1 & 4 & 6 & 4 & 6 & 1 & 3 & - & 2 \\
\hline & 0,04 & 0,18 & 0,41 & 0,56 & 0,78 & 0,82 & 0,93 & 0,93 & 1,00 \\
\hline G6G1 & 2 & 4 & 7 & 3 & 5 & - & 3 & - & 3 \\
\hline
\end{tabular}

$f_{i}$ representa a freqüência observada e $f_{a c}$ corresponde à estimativa da freqüência acumulada.

$f_{i}$ represents the observed frequency and $f_{a c}$ the estimation of accumulated frequency.

Aumento da taxa de passagem de partículas com probabilidade de escape gama distribuída (Figuras $1 b$ e $2 b$ ) e, conseqüentemente, na superestimação do tempo médio de retenção ruminal. Portanto, a opção pelo modelo mais simples, com menor $\mathrm{n}$, acarreta a obtenção de estimativas mais verossímeis dos parâmetros, pois os eventos da retenção do indicador no rúmen-retículo e de seu trânsito, em fluxo laminar pelo restante do trato gastrintestinal, são mais bem explicados pelo modelo. 
parâmetros C e k, há aumento até a ordem de dependência gama 2 e 3 para as épocas 1 (Figuras 1c e 1d) e 2 (Figuras 2c e 2d), respectivamente, seguida, em ambos os casos, de uma queda nas estimativas até a ordem de dependência gama 6 .

Essas duas estimativas correlacionaram-se positivamente $(\mathrm{P}<0,05)$, o que pode ser explicado pelo efeito de diluição do indicador no segundo compartimento do rúmen (partículas pequenas dispersas na fase líquida), aliado à menor taxa de passagem de partículas (probabilidade de escape exponencialmente distribuída).

O modelo G1G1 foi originalmente utilizado para descrever os perfis de excreção fecal do Cr-EDTA, marcador mais indicado para representar o fluxo de líquidos pelo TGI (Grovum \& Williams, 1973). Tal fato pode justificar a inadequação deste modelo à cinética de passagem de partículas, observada neste trabalho.

\section{(a)}

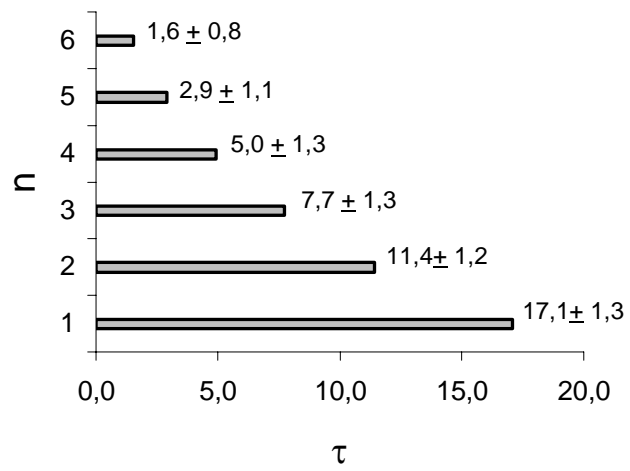

(c)

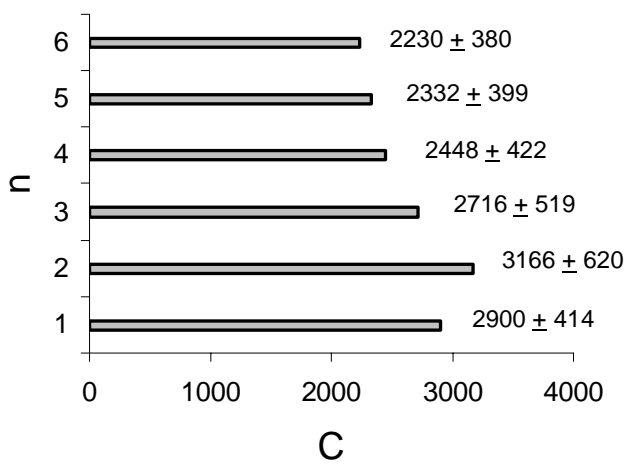

As estimativas pontuais e por intervalo das taxas de passagem associadas às partículas recém-ingeridas tenderam às estimativas das taxas de passagem associadas às partículas dispersas na fase líquida, obtidas com o ajuste do modelo G1G1 em 17 dos 27 perfis obtidos para a época 1 (Figuras $1 \mathrm{~b}$ e $1 \mathrm{~d}$ ) e em 26 dos 27 perfis obtidos durante a época 2 (Figuras 2 b e $2 d$ ). Essa situação também pode ser observada nos resultados apresentados por Ellis et al. (1994) e por Lira (2000), que podem ser atribuídos aos seguintes fatores: 1) ajuste de um modelo que específica dois compartimentos tempo-independentes em seqüência a perfis que possam resultar, em verdade, de três ou mais compartimentos seqüenciais tempo-independentes; 2) existência de dois compartimentos com aproximadamente a mesma massa, não distinguíveis estatisticamente; ou 3) o problema de um dos compartimentos seqüenciais ser tempo-dependente, em vez de

(b)

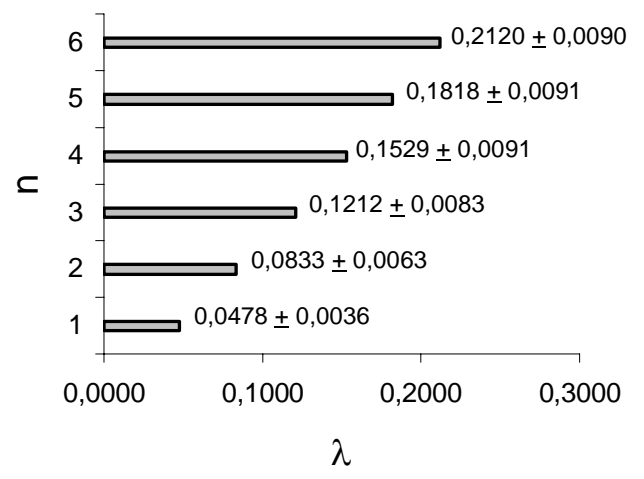

(d)

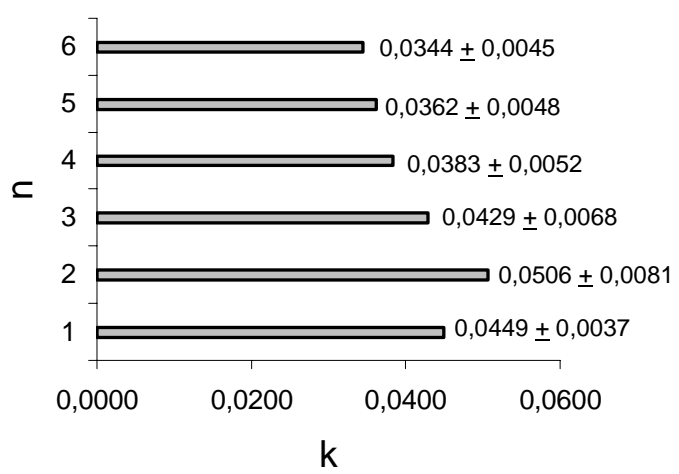

Figura 1 - Estimativas dos intervalos de confiança para os parâmetros $\tau$ (a), $\lambda$ (b), C (c) e $\kappa$ (d) dos respectivos modelos bicompartimentais GnG1, na época 1.

Figure 1 - Estimations of confidence intervals for the parameters $\tau$ (a), $\lambda$ (b), c (c) and $\kappa(d)$ of the respective bicompartimental models GnG1 in season 1. 
dois compartimentos tempo-independentes. Além disso, o fato de $\lambda$ tender a $\mathrm{k}$ é inconsistente com a hipótese de haver dois compartimentos seqüenciais, podendo resultar em consideráveis erros de estimação para $\lambda$ (Ellis et al., 1994). Esta particularidade, entretanto, não foi constatada neste trabalho, visto que as amplitudes estimadas para os intervalos de confiança foram menores com o modelo G1G1, que com os de ordem de dependência superior (Figuras 1b e 2b). Nestes casos, em que as estimativas de $\lambda$ tendem a $\mathrm{k}$, o método de ajuste apresenta problemas de convergência e de singularidade. Uma alternativa para superá-los é a reparametrização do modelo, representada pela equação 2 , que resulta na redução do quadrado médio

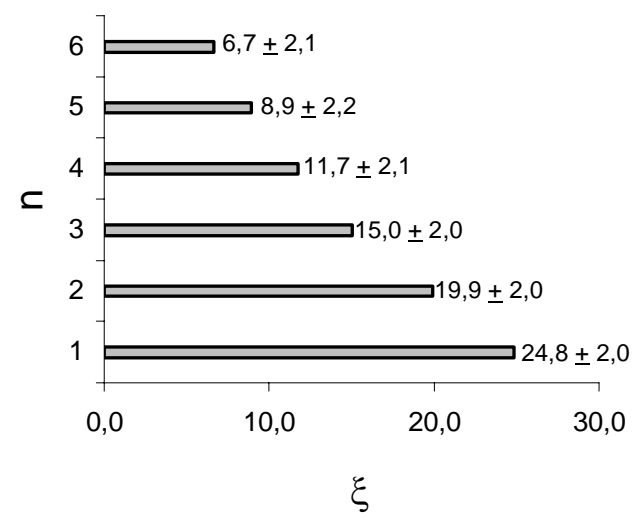

(a)

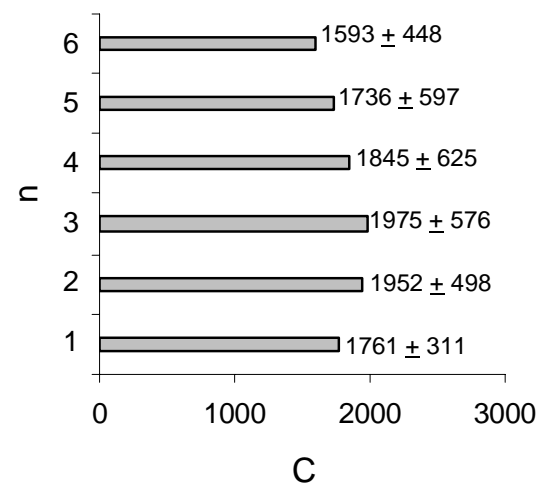

(c) residual e do número de iterações para atingir o critério de convergência e na eliminação do problema de singularidade. Foi também constatada, em alguns casos, a necessidade de reparametrização dos modelos de ordem de dependência superior; dos 27 perfis obtidos durante a época 1, 11 foram ajustados ao modelo G2G1 reparametrizado e, dos 27 perfis obtidos durante a época 2, 12; 6; 3; 1 e 1 foram, respectivamente, ajustados aos modelos reparametrizados deG2G1, G3G1, G4G1, G5G1 e G6G1, representados pelas equações 8, 9, 10, 11 e 12.

Diferenças no tipo de dieta (Pond et al., 1988; Moore et al., 1992; Huhtanen et al., 1995), no tamanho de partículas complexadas com o indicador (Ellis et al., 1979; Quiroz et al., 1988) e na espécie animal

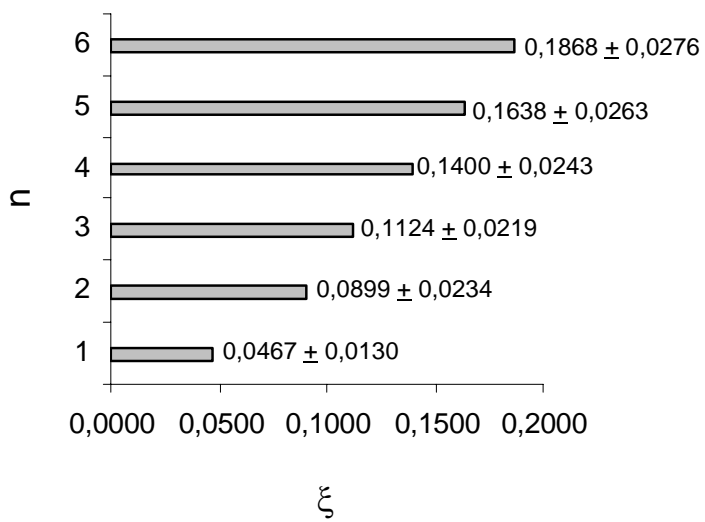

(b)

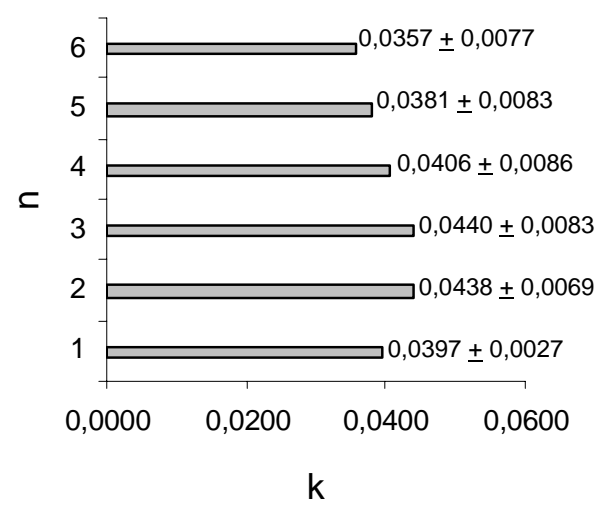

(d)

Figura 2 - Estimativas dos intervalos de confiança para os parâmetros $\tau$ (a), $\lambda$ (b), C (c) e $\kappa$ (d) dos respectivos modelos bicompartimentais GnG1, na época 2.

Figure 2 - Estimations of confidence intervals for the parameters $\tau$ (a), $\lambda(b), C(c)$ and $\kappa(d)$ of the respective bicompartimental models GnG1 in season 2. 
(Quiroz et al., 1988; Moore et al., 1992) podem influenciar a escolha do modelo para descrever a cinética de passagem de partículas. Neste estudo, o material utilizado para complexação com o indicador foi proveniente de pastejo simulado (época 1), tendo sido moído duas vezes em picadeira de metal, enquanto as amostras referentes à época 2 foram obtidas por meio de novilhos fistulados no esôfago, sem sofrer qualquer moagem.

Estudando modelos não-lineares para descrever a cinética de passagem, Quiroz et al. (1988) concluíram que o modelo biexponencial G1G1 foi o mais apropriado para a fase líquida, visto que a mistura do indicador nesta fase deve ocorrer de forma mais rápida, que na fase sólida, o que reduz a dependência de tempo no processo de excreção do indicador. Em se tratando de fase sólida, os autores relataram que o modelo bicompartimental G2G1 foi o mais versátil para partículas pequenas e médias e que o modelo bicompartimental G3G1 o foi para partículas grandes.

Com base no conceito de que existem no rúmen dois compartimentos, sendo o primeiro constituído de partículas recém-ingeridas (malha filtrante do rúmen) e o segundo de partículas pequenas dispersas na fase líquida (Hungate, 1966), e de que as taxas de passagem, $\lambda$ e k estão associadas a processos que ocorrem nesse segmento do trato gastrintestinal (Ellis et al., 1979), o tempo médio de retenção ruminal (TMRR) para os modelos G2G1 (época 1) e G3G1 (época 2) foi calculado conforme as expressões:

TMRR (G2G1), h $=\frac{2}{\lambda}+\frac{1}{\mathrm{k}} ; \mathrm{e}$

TMRR (G3G1), h $=\frac{3}{\lambda}+\frac{1}{\mathrm{k}}$.

O TMRR é uma variável de grande importância em estudos de nutrição de ruminantes, pois determina o fluxo da digesta pelo trato gastrintestinal, que, no caso das forrageiras tropicais, de modo geral, apresenta valores altos, principalmente em razão do elevado teor de fibra, acarretando baixo consumo voluntário (Kennedy \& Murphy, 1988; Van Soest, 1994).

O TMRR não foi influenciado pelos diferentes níveis de proteína não-degradável no rúmen, apresentando valores médios de 48,7 horas (época 1) e de 59,2 horas (época 2), resultando em taxas de passagem de partículas $\left(\mathrm{k}_{\mathrm{p}}, \mathrm{h}^{-1}\right)$ de 0,0205 e 0,0169, respectivamente, próximas a 0,02, valor sugerido pelo AFRC (1993) para o plano de nutrição equivalente à manu- tenção dos animais. Trabalhando com novilhos mestiços com média de massa corporal de 250 kg, mantidos em pastagem de Brachiaria decumbens, sem suplementação, Lira (2000) encontrou TMRR de 51,1 e 41,5 horas, no inverno e verão, respectivamente. No entanto, McCollum \& Galyean (1985), em estudo com novilhos Hereford, com massa corporal inicial de $214 \mathrm{~kg}$, recebendo feno (61 g PB kg-1 MS e $677 \mathrm{~g} \mathrm{FDN} \mathrm{kg}^{-1} \mathrm{MS}$ ) e farelo de algodão, encontraram efeitos da suplementação protéica sobre o TMRR. De acordo com Ellis (1978) e Caton et al. (1988), diferenças no TMRR resultantes da suplementação protéica ocorrem, normalmente, quando a forragem apresenta teores protéicos inferiores a $60 \mathrm{~g} \mathrm{~kg}^{-1} \mathrm{MS}$, situação não verificada neste estudo.

A diferença de TMRR entre as duas épocas pode ser explicada pelo tamanho da partícula complexada com o indicador, beneficiando o material oriundo da época 1, pois, até certo limite, menor partícula resultará em maior taxa de passagem (Faichney, 1993; Gomes et al., 1994). De acordo com Van Soest (1994), o processamento do material por moagem ou por peletização promove a desestruturação física da parede celular e o aumento da densidade, o que resulta em menor tempo de retenção. Somente na época 1, houve diferença significativa entre os períodos, com o maior valor verificado no período 1 (56,4 a), correspondente ao mês de maio, pois, para os períodos subseqüentes, houve redução de aproximadamente uma unidade entre eles (período $2=45,4$ b; e período $3=44,4$ b), o que pode ser explicado pela amostragem da forrageira, possivelmente com maior participação de colmos e material senescente.

O sucesso em estimar o TMRR com base nos perfis de excreção fecal do indicador depende do seu comportamento ao longo do trato gastrintestinal. Considerando-se que, até o momento, não se conhece nenhum indicador ideal (Udén et al., 1980; Owens \& Hanson, 1992; Faichney, 1993), o uso de um método alternativo que exclua a necessidade do uso do indicador pode ser recomendado (Thiago \& Gill, 1990). Este método de obtenção da estimativa do TMRR da fibra consiste no esvaziamento e na amostragem do conteúdo ruminal em intervalos específicos de tempo (Aitchison et al., 1986; Lascano \& Quiroz, 1990; Dado \& Allen, 1995; Huhtanen \& Kukkonen, 1995). De acordo com Dado \& Allen (1995), o TMRR da fibra é calculado ao se dividir o conteúdo ruminal, em kg, pelo consumo médio, por hora, em kg, de fibra 
indigestível, baseando-se no modelo de primeira ordem de dois compartimentos proposto por Waldo et al. (1972) para digestão de celulose, aplicado para fibra. O método assume que as taxas de passagem da fibra digestível e indigestível são iguais e que a taxa de consumo de fibra indigestível é um bom indicador da taxa de passagem, considerando que ela só pode desaparecer do rúmen por passagem, uma vez que sua digestibilidade seria nula (Waldo et al., 1972). Em estudos utilizando essa técnica, Dado \& Allen (1995) e Huhtanen \& Kukkonen (1995) encontraram valores de TMRR de 41,7 e 60,6 horas para fibra indigestível, respectivamente, próximos aos relatados nas épocas 1 e 2 deste trabalho.

O tempo médio de retenção de líquidos (TMRL) não foi afetado pelos níveis de proteína nãodegradável no rúmen da dieta, apresentando valor médio de 20,6 horas. Essa ausência de efeito observada corrobora os resultados obtidos por Judkins et al. (1987) e Hess et al. (1996), que concluíram que, em novilhos mantidos em pastagens com teores protéicos superiores a $60 \mathrm{~g} \mathrm{~kg}^{-1} \mathrm{MS}$, a suplementação não influi na TMRL, o que contraria os resultados encontrados por Caton et al. (1988). Vale ressaltar que esses autores dosaram o indicador no rúmen, obtendo valores inferiores aos deste trabalho. De acordo com Huhtanen \& Kukkonen (1995), a amostragem do indicador no rúmen subestima o TMRL, em comparação à sua dosagem nas fezes, adotada neste estudo.

\section{Conclusões}

O uso dos modelos $G_{n} G_{1}$ permite que os perfis de excreção fecal de indicadores sejam descritos com qualidade de ajuste satisfatória. Neste estudo, os modelos que melhor se ajustaram aos perfis foram o $G_{2} G_{1}$ e o $G_{3} G_{1}$, respectivamente, para passagem de partículas do capim Brachiaria brizantha obtido durante as épocas 1 e 2 .

A suplementação com PNDR parece não afetar o tempo médio de retenção ruminal de partículas e de fluidos.

\section{Agradecimento}

Ao Instituto Melon de Estudos e Pesquisas e à Fazenda Barreiro Ltda, pelo apoio para a realização deste estudo.

\section{Literatura Citada}

AGRICULTURAL AND FOOD RESEARCH COUNCIL AFRC. Energy and protein requirements of ruminants. Cambridge: CAB International, Cambridge University Press, 1993. 159p.

AITCHISON, E.; GILL, M.; FRANCE, J. et al. Comparison of methods to describe the kinetics of digestion and passage of fibre in sheep. Journal of Science Food Agricultural, v.37, p.1065-1072, 1986.

BRODY, S. Bioenergetics and growth with special reference to the efficiency complex in domestic animals. Baltimore: Reinhold Publishing Corporation, 1945. 1023p.

CATON, J.S.; FREEMAN, A.S.; GALYEAN, M.L. Influence of protein supplementation on forage intake, in situ forage disappearance, ruminal fermantation and digesta passage rates in steers grazing dormant blue grama rangeland. Journal of Animal Science, v.66, n.9, p.2262-2271, 1988.

DADO, R.G.; ALLEN, M.S. Intake limitations, feeding behavior, and rumen function of cows challenged with rumen fill from dietary fiber or inert bulk. Journal of Dairy Science, v.78, n.1, p.118-133, 1995.

DRAPER, N.R.; SMITH, H. Applied regression analysis. New York: John Wiley \& Sons, 1966. 407p.

ELLIS, W.C. Determinants of grazed forage intake and digestibility. Journal of Dairy Science, v.61, n.12, p.1828-1840, 1978.

ELLIS, W.C.; MATIS, J.H.. LASCANO, C. Quantitating ruminal turnover. Federation Proceedings, v.38, n.13, p.2702-2706, 1979.

ELLIS, W.C.; MATIS, J.H.; HILL, T.H. et al. Methodology for estimating digestion and passage kinetics of forages. In: FAHEY JR., G.C. (Ed.). Forage quality, evaluation, and utilization. Madison: American Society of Agronomy, 1994. p.682-756.

FAICHNEY, G.J. Digesta flow. In: FORBES, J.M.; FRANCE, J. (Eds.) Quantitative aspects of ruminant digestion and metabolism. England: Commonwealth Agricultural Bureaux, Cambridge University Press, 1993. p.53-85.

GOMES, B.V.; QUEIROZ, A.C.; FONTES, C.A.A. et al. Estudo das características físico-químicas de fenos e palhas. I. Efeitos sobre a ingestão, digestibilidade aparente e taxa de passagem da matéria seca, pH e concentração de amônia ruminal. Revista da Sociedade Brasileira de Zootecnia, v.23, n.3, p.352-365, 1994.

GROVUM, W.L.; WILLIAMS, V.J. Rate of passage of digesta in sheep. 4. Passage of marker through the alimentary tract and the biological relevance of rate-constants derived from the changes in concentration of marker in faeces. British of Journal Nutrition, v.30, n.3, p.313-329, 1973.

HESS, B.W.; KRYSL, L.J.; JUDKINS, M.B. et al. Supplemental cracked corn or wheat bran for steers grazing endophytefree fescue pasture. Journal of Animal Science, v.74, p.1116-1125, 1996.

HUHTANEN, P.; KUKKONEN, U. Comparison of methods, markers, sampling sites and models for estimating digesta passage kinetics in cattle fed at two levels of intake. Animal Feed Science and Technology, v.52, p.141-158, 1995.

HUHTANEN, P.; JAAKKOLA, S.; KUKKONEN, U. Ruminal plant cell wall digestibility estimated from digestion and passage kinetics utilizing mathematical models. Animal Feed Science and Technology, v.52, p.159-173, 1995. 
HUNGATE, R.E. The rumen and its microbes. New York: Academic Press, 1966. 533p.

JUDKINS, M.B.; WALLACE, J.D.; GALYEAN, M.L. et al. Passage rates, rumen fermentation, and weight change in protein supplemented grazing cattle. Journal of Range Management, v.40, n.2, p.100-105, 1987.

KENNEDY, P.M.; MURPHY, M.R. The nutritional implications of differential passage of particles through the ruminant alimentary tract. Nutrition Research Reviews, v.1, n.1, p.189-208, 1988.

KLEIBER, M. The fire of life. 2.ed. Huntington: Robert E. Krieger Publishing Co., 1975. 453p.

LASCANO, C.; QUIROZ, R. Metodologia para estimar la dinámica de la digestión en rumiantes. In: RUIZ, M.E.; RUIZ, A. (Eds.). Nutrición de rumiantes: guía metodológica de investigación. Analisis biologico y tasa de digestion. San José: IICA-RISPAL, 1990. p.89-104.

LIRA, V.M.C. Utilização de diferentes modelos matemáticos e marcadores para simulação da cinética digestiva e de trânsito do capim braquiária (Brachiaria decumbens Stapf.). Viçosa, MG: Universidade Federal de Viçosa, 2000. 90p. Dissertação (Mestrado em Zootecnia) - Universidade Federal de Viçosa, 2000.

MARTZ, F.A.; BELYEA, R.L. Role of particle size and forage quality in digestion and passage by cattle and sheep. Journal of Dairy Science, v.69, n.7, p.1996-2008, 1996.

McCOLLUM, F.T.; GALYEAN, M.L. Influence of cottonseed meal supplementation on voluntary intake, rumen fermentation and rate of passage of prairie hay in beef steers. Journal of Animal Science, v.60, n.2, p.570-577, 1985.

MOORE, J.A.; POND, K.R.; POORE, M.H. et al. Influence of model and marker on digesta kinetic estimates for sheep. Journal of Animal Science, v.70, p.3526-3540, 1992.

OWENS, F.N.; HANSON, C.F. External and internal markers for appraising site and extent of digestion in ruminants. Journal of Dairy Science, v.75, n.9, p.2605-2617, 1992.

PEREIRA, J.C.; ALMEIDA, M.S.; CECON, P.R. et al. Dinâmica da degradação ruminal por novilhos mantidos em pastagem natural em diferentes épocas do ano. Revista Brasileira de Zootecnia, v.31, n.2, p.740-748, 2002.
POND, K.R.; ELLIS, W.C.; MATIS, J.H. et al. Compartment models for estimating attributes of digesta flow in cattle. British Journal of Nutrition, v.60, n.3, p.571-595, 1988.

QUIROZ, R.A.; POND, K.R.; TOLLEY, E.A. et al. Selection among nonlinear for rate of pasaje studies in ruminants. Journal of Animal Science, v. 66, n.11, p.2977-2986, 1988.

STATISTICAL ANALYSES SYSTEM - SAS. User's guide: statistics. versão 6.12. Cary: 1997.

THIAGO, L.R.L.S.; GILL, M. Consumo voluntário: fatores relacionados com a degradação e passagem da forragem pelo rúmen. Campo Grande: EMBRAPA-CNPGC, 1990. 65p. (Documentos, 43)

UDÉN, P.; COLUCCI, P.E.; Van SOEST, P. J. Investigation of chromium, cerium and cobalt as markers in digesta. Rate of passage studies. Journal Science Food Agricultural, v.31, n.7, p.625-632, 1980.

UDÉN, P.; Van SOEST, P.J. The determination of digesta particle size in some herbivores. Animal Feed Science and Technology, v.7, n.1, p.35-44, 1982.

Van MILGEN, J.; MURPHY, M.R.; BERGER, L.L. A compartmental model to analyze ruminal digestion. Journal of Dairy Science, v.74, n.8, p.2515-2529, 1991.

Van SOEST, P.J. Nutritional ecology of the ruminant. 2.ed. Ithaca: Cornell, 1994. 476p.

VARIAN. Analytical methods. Varian Australia Pty Ltd. Publication No 85-100009-00, revised March 1989. 146p.

WALDO, D.R.; SMITH, L.W.; COX, E.L. Model of cellulose disappearance from the rumen. Journal of Dairy Science, v.55, n.1, p.125-129, 1972.

WILLIAMS, C.H.; DAVID, D.J.; IISMAA, 0. The determination of chromic oxide in faeces samples by atomic absorption spectrophotometry. Journal of Agricultural Science, v.59, n.3, p.381-385, 1962.

Recebido em: 16/02/05

Aceito em: 14/07/05 